\title{
The role of tetraploids in the sexual-asexual cycle in dandelions (Taraxacum)
}

\author{
MH Verduijn, PJ Van Dijk and JMM Van Damme \\ Department of Plant Population Biology, Netherlands Institute of Ecology, PO Box 40, 6666 ZG Heteren, The Netherlands
}

\begin{abstract}
Apomictic plants often produce pollen that can function in crosses with related sexuals. Moreover, facultative apomicts can produce some sexual offspring. In dandelions, Taraxacum, a sexual-asexual cycle between diploid sexuals and triploid apomicts, has been described, based on experimental crosses and population genetic studies. Little is known about the actual hybridization processes in nature. We therefore studied the sexual-asexual cycle in a mixed dandelion population in the Netherlands. In this population, the frequencies of sexual diploids and triploids were 0.31 and 0.68 , respectively. In addition, less than $1 \%$ tetraploids were detected. Diploids were strict sexuals, triploids were obligate apomicts, but tetraploids were most often only partly apomictic, lacking certain elements
\end{abstract}

of apomixis. Tetraploid seed fertility in the field was significantly lower than that of apomictic triploids. Field-pollinated sexual diploids produced on average less than $2 \%$ polyploid offspring, implying that the effect of hybridization in the $2 x-3 x$ cycle in Taraxacum will be low. Until now, $2 x-3 x$ crosses were assumed to be the main pathway of new formation of triploid apomicts in the sexual-asexual cycle in Taraxacum. However, tetraploid pollen donors produced 28 times more triploid offspring in experimental crosses with diploid sexuals than triploid pollen donors. Rare tetraploids may therefore act as an important bridge in the formation of new triploid apomicts. Heredity (2004) 93, 390-398. doi:10.1038/sj.hdy.6800515 Published online 7 July 2004

Keywords: Taraxacum; apomixis; sexual-asexual cycle; hybridization; polyploidy

\section{Introduction}

Most angiosperms reproduce sexually through seeds, but in more than 140 genera at least some taxa can produce seeds parthenogenetically (Carman, 1998). These apomicts produce clonal offspring that are genetically identical to the mother plant. However, apomicts are rarely completely cut off from sexual reproduction. In facultative apomicts, some residual sexual seed set is left. Even in obligate apomicts sexual reproduction is not completely eliminated, because apomictic plants often produce at least some functional pollen. Therefore, when sexuals and apomicts co-occur, sexuals can produce apomictic offspring and apomicts can produce sexual offspring, resulting in a sexual-asexual cycle (De Wet, 1968; De Wet and Harlan, 1970; Savidan and Pernes, 1982; Berthaud, 2001).

In the sexual-asexual cycle, genes can flow from the asexual lineages into the sexual gene pool, whereas in the other direction new asexual lineages are formed. The relative levels of the gene flows do not only affect the composition of the gene pools, but will also affect the coexistence of sexuals and asexuals. Population genetic models predict a rapid decline of the sexual outcrossing population when apomixis is controlled by a single dominant gene (Charlesworth, 1980; Marshall and Brown, 1981; Joshi and Moody, 1998).

In dandelions, Taraxacum, a sexual-asexual cycle, has been proposed by Richards (1970a, 1997) and Morita et al

Correspondence: $\mathrm{MH}$ Verduijn, University of Newcastle, School of Biology, Ridley Building, Newcastle upon Tyne, NE1 7RU, UK.

E-mail: m.h.verduijn@ncl.ac.uk

Received 11 November 2003; accepted 6 May 2004; published online 7 July 2004 (1990b). The diploid $(2 n=2 x=16)$ dandelions invariably reproduce sexually and are generally outbreeding due to a sporophytic self-incompatibility (SI) system (Okabe, 1956). Apomicts are mostly triploid $(2 n=3 x=24)$ and generally obligately apomictic. In experimental sexual diploid-apomictic triploid crosses, diploid offspring as well as some triploid and tetraploid offspring are produced (reviewed by Morita et al, 1990b). This suggests that genes can readily flow from the triploid apomicts into the diploid sexual gene pool. However, allozyme markers indicated that nearly all diploid offspring were produced by induced selfing and not caused by hybridization (Morita et al, 1990a; Tas and Van Dijk, 1999). Inviable aneuploid pollen from triploid apomicts causes a mentor effect for self-pollen of diploid sexuals, leading to a breakdown of the SI system (Morita et al, 1990b). Nonetheless, Tas and Van Dijk (1999) could confirm some diploid and polyploid offspring as true hybrids in sexual diploid-apomictic triploid crosses by allozyme markers. Reciprocal apomictic triploid-sexual diploid crosses produce generally only apomictic triploid offspring, but occasionally also low numbers of diploid offspring have been reported (Richards, 1970a; Müller, 1972). This indicates that gene flow from triploid apomicts to diploid sexuals could also occur through facultative apomixis.

In Europe, mixed sexual-asexual populations of Taraxacum section Ruderalia are locally common (Den Nijs and Sterk, 1980, 1984a,b; Elzinga et al, 1987; Roetman et al, 1988). In these populations, there is an overlap in the flowering period between the asexuals and the sexuals and gene flow between the two cytotypes is likely to occur (Verduijn et al, 2004). Menken et al (1995) concluded on the basis of shared allozyme polymorphisms 
in a number of sympatric populations in western and central Europe that local gene flow between sexuals and apomicts was extensive.

The idea of a sexual-asexual cycle in Taraxacum is based on experimental crosses and gene pool analyses. Knowledge about the actual processes in nature is nearly absent, especially concerning the formation frequency, the breeding system and the fertility of new polyploid hybrids. Facultative apomicts have been occasionally reported, but their frequency in nature is still unknown. Tetraploids are formed in about equal frequencies as triploids in sexual diploid-apomictic triploid crosses (Tas and Van Dijk, 1999), but are rare in nature (Richards, 1997; Meirmans et al, 1999; Calame and Felber, 2000).

The fertility of polyploid hybrids might be low depending on their formation pathway. Tas and Van Dijk (1999) found that triploid hybrids from experimental sexual-apomict crosses were not always apomicts, but segregated for apomixis and the degree of apomixis. Apomictic reproduction in Taraxacum involves three developmental processes or elements: diplospory (first meiotic division restitution), parthenogenetic embryo growth and autonomous endosperm development. Some of the triploid hybrids lacked one or more elements of apomixis, probably due to recombination of genes controlling these elements during pollen meiosis (Van Dijk et al, 1999). The tetraploid hybrids of the same study were all apomictic, but some showed reduced seed set. Yet, because tetraploids produce fertile diploid pollen, they may play an important role in the formation of new triploid apomicts.

The aim of the present study is to quantify some of the processes that affect the dynamics of the sexual-asexual cycle in a natural Taraxacum population. To this end, we studied the rate of polyploid offspring formation on diploid sexual mothers in the field and characterized the breeding system of diploids, triploids and the rare tetraploids.

\section{Materials and methods}

\section{Field sampling and genotyping}

The studied population was located near Wageningen, the Netherlands, on a summer dike and its foreland, along the river Rhine (for a detailed description, see Verduijn et al, 2004). Samples taken in 1993 and 1995 indicated that sexual diploid and asexual triploid Taraxacum section Ruderalia plants grew intermingled at this site. In 1999 more than 2100 plants were sampled and analysed by flow cytometry (Ploidy Analyser; Partec, Muenster, Germany, see Tas and Van Dijk, 1999) to determine the cytotype frequencies of established plants.

In 1993, 1995 and 2000, a random sample of diploid seed heads was collected to determine the frequency of polyploid hybrid offspring on diploid sexual mothers. Seed heads were collected before opening, to avoid contamination by dispersed seeds from established triploid plants in the population. From each seed head, 20-50 seeds were germinated and the ploidy level of the seedlings was determined. In 1993, this was carried out by mitotic chromosome number counts (see Tas and Van Dijk 1999), in the other 2 years by flow cytometry.
Besides diploids and triploids, some established tetraploids were detected in an extensive survey in 1999. These tetraploids were mapped in a grid for further study in 2000. Leaf samples from established tetraploids were preserved in a high-salt-concentrate CTAB solution (Rogstad, 1992) for genotyping, to investigate the clonal descent and pathway of formation of tetraploids. DNA was isolated by the $\mathrm{NaOH}$ extraction method of Wang et al (1993). PCR conditions for the four microsatellite loci MSTA 61, MSTA 64, MSTA 72 and MSTA 78 were as described by Falque et al (1998).

In addition, seeds were collected from one triploid and one tetraploid plant growing in the foreland. After germination, all seedlings were cytotyped by flow cytometry and genotyped for the four microsatellite loci MSTA 53, MSTA 61, MSTA 72 and MSTA 78 (Falque et al, 1998). The PCR products were analysed on an ALF Express II sequencer (Amersham Pharmacia Biotech, Uppsala, Sweden).

\section{Reproductive measurements}

In spring 2000, the fertility in the field of a subset of diploids and triploids and of all the tetraploids was investigated. The number of capitula produced per plant was recorded and from 22 individuals the number of seeds (achenes) per capitulum was determined (the $\mathrm{G}_{0}$ generation: $2 x$ : seven ind., $3 x$ : 11 ind., $4 x$ : four ind.). Seed set was determined as the percentage of developed seeds among all seeds within a seed head. Developed seeds are plump and brown, whereas undeveloped seeds are narrow, papery and unpigmented (Richards, 1970b). Germination rate was determined for each plant (two petri dishes; 50 brown seeds per dish, on a wet filter paper; $16 \mathrm{~h}, 21^{\circ} \mathrm{C}$ light, $8 \mathrm{~h} 15^{\circ} \mathrm{C}$ dark). Viable seed set was calculated as the product of seed set and germination rate.

\section{Breeding system investigations}

In 2000, the breeding systems of 10 different $G_{0}$ plants ( $2 x$ : four ind., $3 x$ : three ind., $4 x$ : three ind.) and their descendants $\left(G_{1}\right.$ generation) were studied. Per $G_{0}$ plant 50 seeds were germinated from several field-pollinated capitula. The ploidy levels of all seedlings from diploid and tetraploid mother plants were determined by flow cytometry. The triploids were assumed only to produce triploid offspring.

The $G_{1}$ generation was used to test for spontaneous seed set (apomixis) and for seed set and pollen fertility in interploidy crosses. Growth and flowering induction conditions were as described in Tas and Van Dijk (1999). At 2 days before opening, the flower heads were covered with a paper bag, to avoid contamination by outcross pollen. In the isolation treatment, the paper bag was kept around the head to test for spontaneous seed set. Reciprocal interploidy crosses were made by rubbing the capitula of the two parent plants together, and this was repeated the next day if both flowers were still open.

For each seed head, seed set was determined as above. The ploidy level of the isolation and cross progenies $\left(G_{2}\right.$ generation) was determined by flow cytometry to determine the mode of reproduction of the parent plants. A plant that is not (fully) apomictic will produce an offspring that has a lower or higher ploidy level than itself. To distinguish the different origins of the proge- 
nies, the terminology of Harlan and de Wet (1975) was adopted. Egg cells can be either reduced $(n)$ or unreduced $(2 n)$. Apomictically produced offspring are produced from unreduced egg cells without fertilization, indicated as $2 n+0$. As in Taraxacum the capability for unreduced egg cell formation (diplospory), and for parthenogenesis, can be separated by recombination at pollen meiosis (Van Dijk et al, 1999), three more offspring types are possible: (1) fertilization of an unreduced egg cell $(2 n+n),(2)$ fertilization of a reduced egg cell $(n+n)$ or (3) parthenogenetic development of a reduced egg cell resulting in a 'polyhaploid' $(n+0)$ (Nogler, 1984). Note that ' $n$ ' can represent different chromosome numbers and that only in diploids ' $n$ ' equals ' $x$ ', the basic chromosome number. This precise distinction between ' $n$ ' and ' $x$ ' is necessary to distinguish between the various offspring types, and to avoid confusion when working with triploids and other anorthoploids (Nogler, 1984).

\section{Statistical data analysis}

A generalized linear model (GLM procedure of SAS v8, SAS Institute Inc. 1999) was used to test for differences in the number of capitula produced by flowering plants between the three ploidy levels. Contrasts were laid between $2 x$ versus $3 x$ and $2 x, 3 x$ versus $4 x$.

A generalized linear model (GLM procedure of SAS v8, SAS Institute Inc. 1999) was used and heterogeneity of sampling variances was assessed by the HOVTEST = LEVENE option in SAS v8 to test for differences in the number of seeds per capitulum between the three ploidy levels and plants. As most plants produced more than one capitulum, plant was nested within the ploidy level. Contrasts were laid between $3 x$ versus $2 x, 4 x$ while testing the total number of seeds and between $4 x$ versus $2 x, 3 x$ while testing the number of developed seeds.

Differences between ploidy levels in the ratio of developed seeds to the total number of seeds (seed set) and proportion of seeds that germinated (germination rate) were tested using a log-linear model with a binomial error distribution (GENMOD procedure of SAS v8, SAS Institute Inc. 1999). The main effects of ploidy level and plant nested within the ploidy level were tested. Contrasts were laid between $2 x$ versus $3 x$ and $2 x, 3 x$ versus $4 x$.

The same GENMOD procedure was used to test the seed set and germination of seeds from the cross types $2 x-3 x, 2 x-4 x, 3 x-2 x$ and $4 x-2 x$. The main effect of cross type was modelled. Contrasts were laid between cross type $2 x-3 x$ versus $2 x-4 x$ and $3 x-2 x$ versus $4 x-2 x$.

\section{Results}

\section{Frequency of polyploid offspring on diploid sexual mothers}

To determine the frequency of polyploid offspring on sexual diploid plants in the field, seed heads from randomly selected diploid plants were collected (16 in 1993, 38 in 1995 and seven in 2000). In all the 3 years, the great majority of the offspring were diploids (97.2, 97.5 and $100 \%$, respectively). In the 1993 and 1995 samples, the frequencies of triploid offspring on diploid mothers were 2.3 and $1.7 \%$. In both years, the frequencies of tetraploids on diploid mothers were lower than those of triploids, namely 0.5 and $0.8 \%$, respectively (Table 1 ). No aneuploids were detected in the samples.

Table 1 Comparison of the results of crossing experiments of previous studies with this study

\begin{tabular}{|c|c|c|c|c|c|c|c|}
\hline Cross type & $\mathrm{N}$ & Seed set & $\# F$ & $2 x \%$ & $3 x \%$ & $4 x \%$ & Reference \\
\hline \multicolumn{8}{|c|}{ Experimental crosses } \\
\hline $2 x-3 x^{a}$ & 14 & $10 \%$ & 156 & 91.7 & 3.2 & 5.1 & This study \\
\hline $2 x-3 x^{\mathrm{a}}$ & 11 & $22 \%$ & 245 & 91.0 & 6.1 & 2.9 & Tas and Van Dijk (1999) \\
\hline $2 x-3 x^{b}$ & ng & $4-25 \%$ & 183 & 87.4 & 7.7 & 4.9 & Morita et al (1990a) \\
\hline $2 x-3 x^{c}$ & 3 & Low & 39 & 92.3 & 0.0 & 7.7 & Hughes and Richards (1988) \\
\hline $2 x-3 x^{\mathrm{a}}$ & 3 & Low & 37 & 100.0 & 0.0 & 0.0 & Jenniskens et al (1984) \\
\hline $2 x-3 x^{a}$ & 5 & nd & 269 & 96.7 & 3.3 & 0.0 & Müller (1972) \\
\hline $2 x-3 x^{\mathrm{d}}$ & 3 & Low & & & & 0.0 & Richards (1970b) \\
\hline $2 x-4 x^{\mathrm{a}}$ & 24 & $39 \%$ & 1014 & 13.8 & 86.1 & 0.1 & This study \\
\hline $2 x-4 x^{\mathrm{e}}$ & 1 & Low & & 100.0 & 0.0 & 0.0 & Richards (1970b) \\
\hline $2 x-4 x^{\mathrm{f}}$ & 1 & nd & & & 100.0 & & Fürnkranz (1961) \\
\hline \multicolumn{8}{|c|}{ Open pollination in the field } \\
\hline $2 x-3 x^{a, g}$ & 7 & $79 \%$ & 164 & 100.0 & 0.0 & 0.0 & This study (2000) \\
\hline $2 x-3 x^{\mathrm{a}, \mathrm{g}}$ & 38 & nd & 473 & 97.5 & 1.7 & 0.8 & This study (1995) \\
\hline $2 x-3 x^{\mathrm{a}, \mathrm{g}}$ & 16 & nd & 391 & 97.2 & 2.3 & 0.5 & This study (1993) \\
\hline $2 x-3 x^{\mathrm{a}, \mathrm{h}}$ & 3 & nd & 64 & 43.7 & 45.3 & 11.0 & Sterk (1987) \\
\hline
\end{tabular}

All crossings were performed with diploid $(2 n=16)$ Taraxacum s. Ruderalia dandelions as mother (except for ${ }^{b}$ ). Note that some of the interploidy crosses are wide crosses between sections. $N=$ the number of crosses performed or the number of seed heads collected from the field. $F=$ offspring. For each study, the percentages of diploid, triploid and tetraploid offspring are given. nd $=$ not determined. ng $=$ not given.

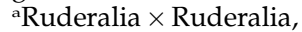

'Mongolica $\times$ Ruderalia,

cRuderalia $\times$ Hamata,

dRuderalia $\times$ Fontana/Ruderalia,

eRuderalia $\times$ Obovata,

${ }^{\mathrm{f}}$ Ruderalia $\times$ Palustria.

Bopen pollination in a mixed $2 x-3 x$ population.

${ }^{\mathrm{h}}$ Open pollination in a pure triploid population. 
Frequency of established cytotypes

In the extensive search for established tetraploids in 1999, a total of 2129 plants were screened by flow cytometry. The overall frequency of diploid plants was 0.31 , that of triploid plants 0.68 . Only 12 tetraploid plants were found (frequency: 0.006). In 2000, nine of these tetraploid plants were located again (six adults and three juveniles) and sampled, and quantitative measurements were taken. All the nine tetraploids had unique fourmicrosatellite locus genotypes. The tetraploids were highly heterozygous; in most cases four different alleles per locus were present.

\section{Fertilities of cytotypes in the field}

The average number of capitula per flowering plant for the diploids $(2.13 \pm 0.22)$ did not differ significantly from the triploids $(2.25 \pm 0.27)(\mathrm{df}=1, P=0.94)$. The average number of capitula per plant in the tetraploids $(4.60 \pm 1.63)$ was significantly higher than that of the other two ploidy levels because two tetraploid plants produced more capitula $(\mathrm{df}=1, P<0.001)$.

For 22 plants in the field the seed set was determined (Figure 1). Overall average number of seeds (developed and undeveloped) per capitulum was $150 \pm 5.90$. The triploid capitula contained on average 138 seeds (devel-

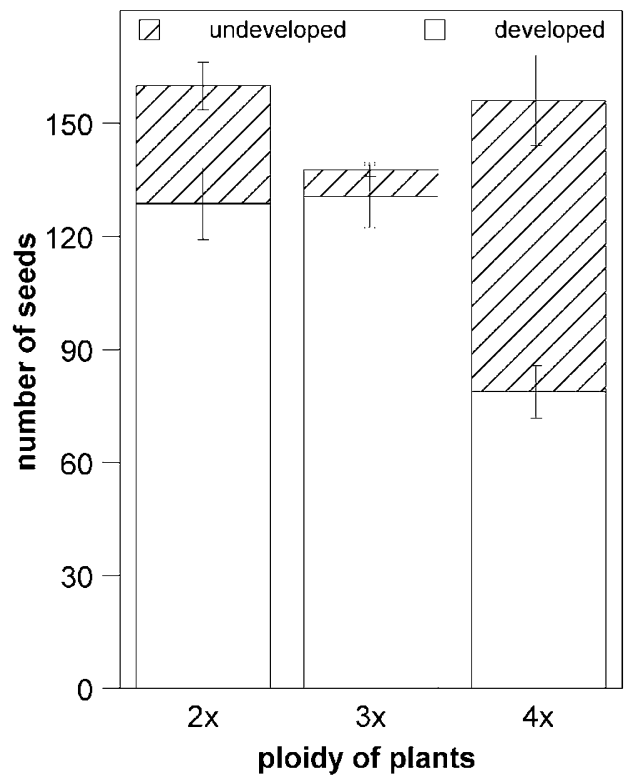

Figure 1 The average number of developed (white) and undeveloped (hatched) seeds produced per capitulum. Seeds were produced by $G_{0}$ diploid sexual $(N=7)$, triploid asexual $(N=11)$ and tetraploid $(N=4)$ dandelions after natural open pollination in a mixed population. oped and undeveloped), which was significantly less than diploid (163 seeds) and tetraploid capitula (156 seeds) $(\mathrm{df}=1, P<0.01)$. However, triploid apomictic seed set was significantly higher than diploid sexual seed set (0.94 vs $0.79 ; \mathrm{df}=1, P<0.001$ ).

The tetraploids produced a significantly lower number of developed seeds (Figure 1) than both diploids and triploids $(\mathrm{df}=1, P \leqslant 0.001)$. Half of their seeds did not develop, resulting in a seed set of 0.54 , significantly lower than the seed set of both the diploid and triploid plants $(\mathrm{df}=1, P<0.001)$. There was large variation in seed set between the four tetraploid plants, ranging from 0.22 to 0.88 (Table 2 and Figure 2).

The germination rate of the tetraploids was also highly variable, ranging from 0.06 to 0.76 (Table 2 and Figure 2). The average germination rate for the tetraploids was lower than that of the other two ploidy levels $(\mathrm{df}=1$, $P<0.001$ ). The low seed set in tetraploids and the generally low germination rate resulted in a very low viable seed set (Table 2). One of the tetraploids (Tetra 1) in particular had a low seed set $(0.29 \pm 0.04)$ and germination rate $(0.11 \pm 0.05)$ (Figure 2). In addition, in the first few weeks after potting, many seedlings from tetraploids died while all seedlings of diploid and triploid plants survived. The germination rate of seeds from triploid plants was significantly lower than that of

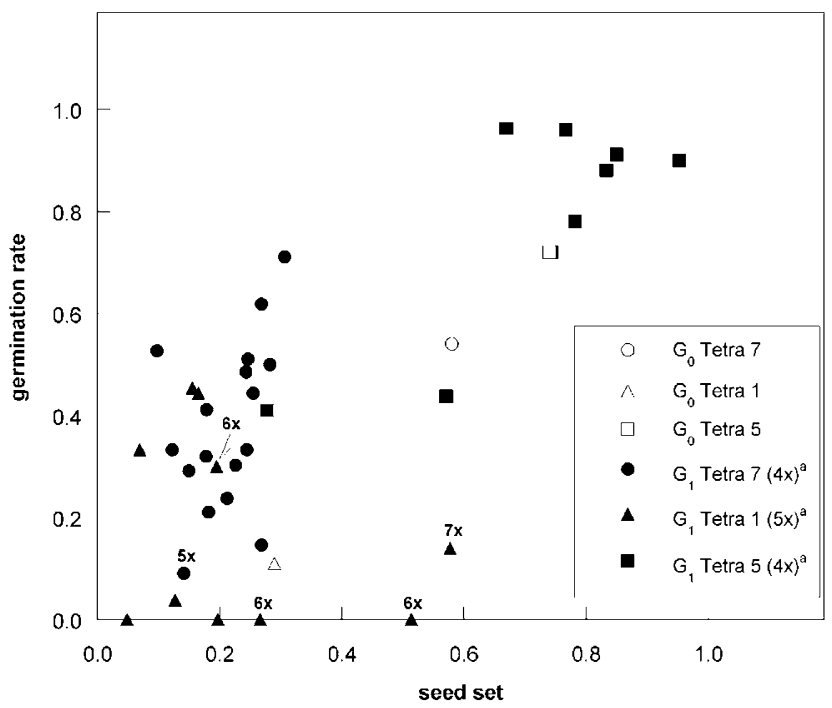

Figure 2 Seed set versus germination rate in tetraploid dandelions. Open symbols represent capitula of the three open pollinated tetraploid plants from the field $\left(\mathrm{G}_{0}\right)$ and closed symbols represent capitula of the $G_{1}$ plants after crossing with diploid plants. ${ }^{a}$ Most common ploidy level; higher ploidy levels are indicated in the graph.

Table 2 Fertility of the different cytotypes in a mixed population after natural pollination $\left(\mathrm{G}_{0}\right.$ generation)

\begin{tabular}{lrccccc}
\hline Ploidy level & $\mathrm{N}$ & Seed set & Range & Germination & Range & Viable seed set \\
\hline $2 x$ & 7 & $0.79 \pm 0.04 \mathrm{a}$ & $0.51-0.95$ & $0.98 \pm 0.009 \mathrm{a}$ & $0.89-1.00$ & 0.77 \\
$3 x$ & 11 & $0.94 \pm 0.01 \mathrm{~b}$ & $0.78-1.00$ & $0.90 \pm 0.018 \mathrm{~b}$ & $0.73-1.00$ & 0.85 \\
$4 x$ & 4 & $0.54 \pm 0.05 \mathrm{c}$ & $0.22-0.88$ & $0.48 \pm 0.096 \mathrm{c}$ & $0.06-0.76$ & 0.26 \\
\hline
\end{tabular}

Per ploidy averages (with standard error and range) of the seed set per capitulum and the germination rate are given. Viable seed set is the product of seed set and germination rate. $N=$ number of plants. Different letters indicate significant differences between ploidy levels at the $P=0.05$ level. 
diploid plants ( $\mathrm{df}=1, P<0.001)$, but the viable seed set of triploids was still the highest (Table 2).

\section{Breeding systems of the cytotypes}

All diploid plants from the field sample collected in 2000 $\left(\mathrm{G}_{0}\right)$ produced exclusively diploid offspring. Crosses indicated that diploid $G_{1}$ plants only produced reduced egg cells that need fertilization (Figure 3 ). Of the 19 capitula that were given the isolation treatment, 14 produced no seed at all. The remaining five produced a few brown seeds; however, these did not germinate and no embryos were observed after dissecting. This suggests that the diploids were self-incompatible sexuals.

The single triploid plant sampled in the foreland produced besides 22 triploid plants $(2 n+0)$ also two tetraploid plants. Microsatellite analysis proved that the two tetraploid offspring were produced by cross-fertilization of unreduced egg cells $(2 n+n)$. The triploid $\mathrm{G}_{1}$ plants from the other $G_{0}$ triploids produced after

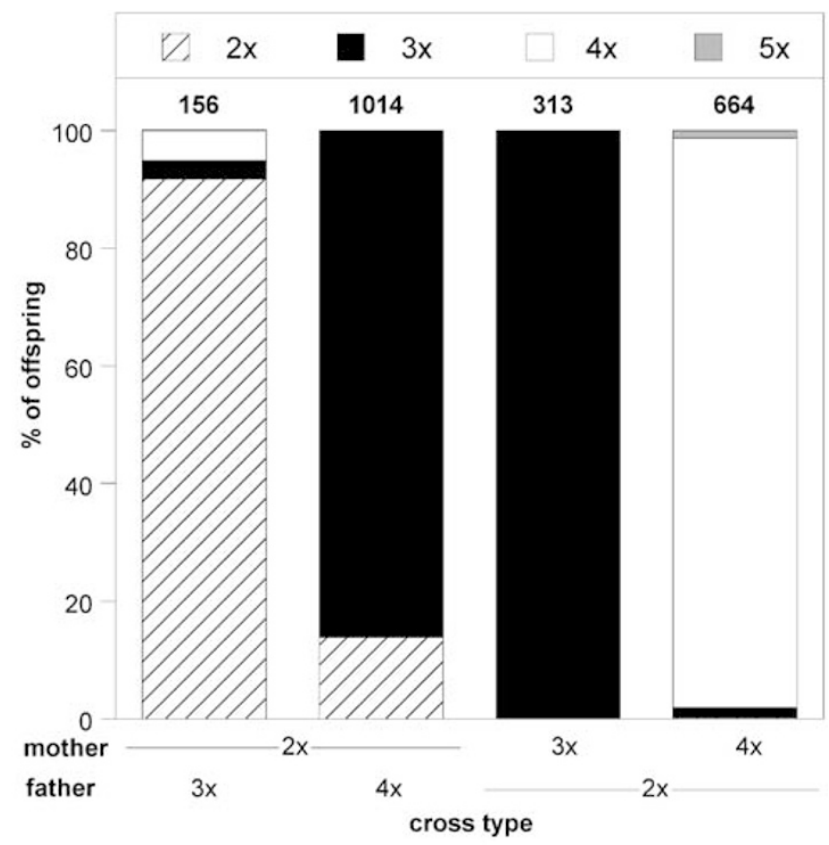

Figure 3 Progeny composition of reciprocal crosses between diploid $G_{1}$ plants and $G_{1}$ plants of a higher ploidy level. The ploidy level of the offspring is given as the percentage per cross type. The two bars on the left represent crosses with diploid seed parents, the two bars on the right represent crosses with diploid pollen parents. Above each bar the total number of offspring is given. crossing with a diploid only triploid offspring (Figure 3). All seed heads from triploid plants had good seed set (also in the isolation treatment) and high germination rates (Table 3), suggesting that they were obligate apomicts.

The four investigated $G_{0}$ tetraploids and their $G_{1}$ offspring differed in their breeding system, as indicated by the ploidy levels of their progenies and, therefore, are described individually.

Tetra 5 - This tetraploid lineage produced only tetraploid offspring after pollination (Figure 4). Seed set and germination rate were high. The seed set of the $G_{1}$ capitula $(N=2)$ in the isolation treatment (0.77) was comparable to the seed set in the crosses. Therefore, we conclude that Tetra 5 is an obligate apomictic lineage.

Tetra 7 - This tetraploid lineage produced mainly tetraploid progeny after pollination, but occasionally offspring with higher or lower ploidy levels occurred (Figure 4). Seed set and germination rate in this lineage were lower than those of Tetra 5 (Figure 2). The $\mathrm{G}_{1}$ capitula $(N=9)$ in isolation had an average seed set of 0.09 . Of those seeds $28 \%$ germinated, and of the 32 surviving seedlings 28 were tetraploid, two were hypotetraploid and two were hypertriploid. We conclude that this tetraploid lineage produces mostly unreduced egg cells that develop mostly parthenogenetically $(2 n+0)$, but rarely can be fertilized $(2 n+n)$. The occasional reduced egg cells in this tetraploid lineage can either develop parthenogenetically $(n+0)$ or after fertilization $(n+n)$.

Tetra 1 - All field progeny of this tetraploid were of a higher ploidy level than the mother. Penta-, hexa- and heptaploid $G_{1}$ plants are likely formed by fertilization of an unreduced $4 x$ egg cell by haploid, diploid and triploid pollen, respectively. Figure 4 shows that this lineage has a tendency to increase its ploidy number upon pollination $(2 n+n)$. Some offspring can either be explained as $(n+n)$ or as $(2 n+0)$ offspring (Figure 4$)$. For the four capitula tested in isolation, the seed set was very low (average 0.04) and none of the seeds germinated. It seems likely that this lineage produces unreduced egg cells (diplospory), but lacks parthenogenesis.

Tetra F - This tetraploid plant from the foreland produced tetraploids $(2 n+0 ; 44 \%)$ and offspring with a higher ploidy level $(2 n+n ; 56 \%)$. No $\mathrm{G}_{1}$ progeny were raised for breeding system testing in this pedigree. The higher polyploid progeny inherited all microsatellite alleles from the mother and one or more paternal alleles, indicating fertilization of unreduced egg cells $(2 n+n$, data not shown).

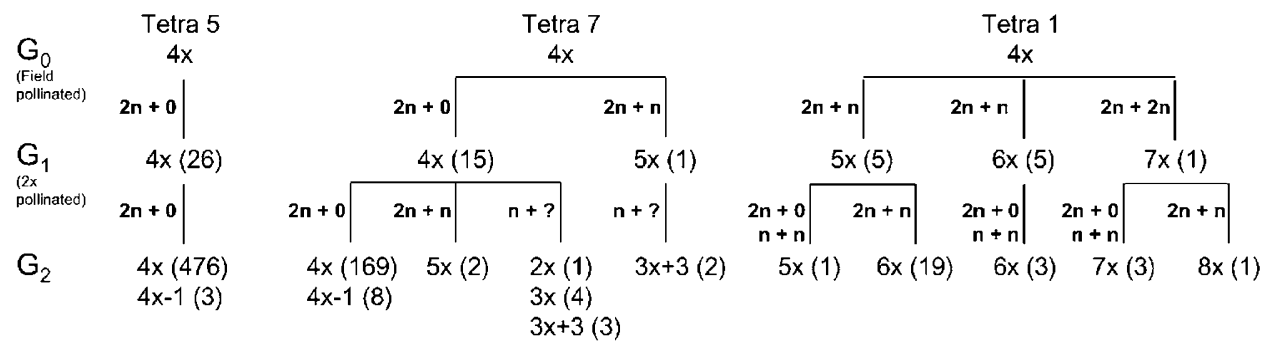

Figure 4 Changes in ploidy level over two generations for three tetraploid plants. The $\mathrm{G}_{1}$ was derived from open pollination in the mixed $2 x-$ $3 x$ population. The $\mathrm{G}_{2}$ was derived after pollination with diploid plants. The types of offspring are classified according to Harlan and De Wet (1975); see Materials and methods. The number of offspring is indicated between parentheses. 
Table 3 Fertility of the different cytotypes after crossing $\left(G_{1}\right.$ generation)

\begin{tabular}{lccccc}
\hline Cross type & $\mathrm{N}$ & Seed set & Range & Germination & Viable seed set \\
\hline $2 x-3 x$ & 14 & $0.10 \pm 0.03$ & $0.02-0.38$ & $0.80 \pm 0.07$ & $0.25-1.00$ \\
$2 x-4 x$ & 24 & $0.39 \pm 0.05$ & $0.06-0.81$ & $0.69 \pm 0.07$ & 0.09 \\
$3 x-2 x$ & 17 & $0.88 \pm 0.03$ & $0.63-0.98$ & $0.80 \pm 0.07$ & 0.30 \\
$4 x-2 x$ & 25 & $0.38 \pm 0.06$ & $0.10-0.95$ & $0.53 \pm 0.05$ & $0.00-0.94$ \\
\end{tabular}

Per cross-type averages (with standard error and range) are given of the seed set per head and the germination rate. Viable seed set is the product of seed set and germination rate. $N=$ number of crosses.

\section{The pollen function of the cytotypes}

Diploid plants were crossed with triploid and tetraploid pollen donors to investigate the effect of the ploidy level of the pollen donor on seed set and germination (Table 3 ), selfing and the number of triploid offspring formed (Figure 3 and Table 1).

The seed set in diploid plants after crossing with triploid apomicts $(2 x-3 x$ cross type) was low $(10 \%)$ and significantly lower than that in the $2 x-4 x$ cross type (almost $40 \%)(\mathrm{df}=1, P<0.001)$. The germination rate was not significantly different between cross types $2 x-3 x$ and $2 x-4 x(\mathrm{df}=1, P=0.59)$. On average, the viable seed set in $2 x-4 x$ crosses was three times higher than in $2 x-3 x$ crosses (Table 3).

The percentage of triploid offspring depended strongly on the ploidy level of the pollen donor (Figure 3). In $2 x-3 x$ crosses $92 \%$ of the viable seeds were diploid, only $3 \%$ were triploid and $5 \%$ were tetraploid, whereas in $2 x-4 x$ crosses less than $14 \%$ were diploid and $86 \%$ were triploid (Figure 3 and Table 1).

The inheritance of apomixis was investigated in the triploid progenies of two $2 x$-Tetra 5 crosses. In cross no. 16, five out of 35 tested triploid offspring plants spontaneously set seeds and were thus apomictic. In cross no. 17, seven out of 73 tested triploid offspring plants were apomictic. Taken the two crosses together, this is $11.1 \%$. This demonstrates that triploid progenies can inherit apomixis from their tetraploid fathers.

\section{Discussion}

\section{Formation of polyploids on diploid sexual mothers}

Samples taken in 3 years indicate that the rates of formation of polyploid seeds on diploid sexual mothers in the field are on average less than $2 \%$. These rates are considerably lower than those commonly reported in $2 x-$ $3 x$ experimental crosses, including those of our own study (Table 1). The average rate of polyploid formation of the four most extensive experimental crosses in Table 1 is almost $8 \%$. When isolated diploid sexual plants were placed in a pure triploid apomictic population, even more polyploid offspring were found (more than 50\%) (Sterk, 1987). The different outcomes are probably due to the presence of numerous other diploid plants in our mixed population $(31 \%)$, whereas in the other studies no haploid out-cross pollen was present. It is likely that pollen competition plays an important role in the field. Pollen produced by triploids is highly unbalanced and euploid pollen is only produced at very low frequencies (Jenniskens et al, 1984; Van Baarlen et al, 2000). If pollen from other diploids is present, this will outcompete the pollen from triploids. To conclude, polyploids are formed on sexual diploids in mixed populations but only at a very low rate, and the rate of hybridization is positively correlated with the relative frequency of triploid plants around the diploid mother plant.

\section{Frequency of tetraploids in the field}

Both experimental and field studies show that tetraploids are produced at roughly similar rates to triploids in $2 x-3 x$ crosses (Table 1 ). In contrast, the frequencies of tetraploids among established plants in the field are always much lower than those of triploids. In the extensive studies on the European cytogeography of section Ruderalia (eg Sterk et al, 1982; Den Nijs and Sterk, 1984a; Roetman et al, 1988), no tetraploids were reported. This may be due to the inadequacy of the pollen size method of Tschermak-Woess (1949) that was used, because tetraploids often produce regularly sized pollen like diploids do and therefore will go unnoticed. In the surroundings of Vienna, Fürnkranz (1960) found some tetraploids in ' $T$. officinale', identified by chromosome numbers. More recently, low frequencies $(<1 \%)$ of tetraploids in Ruderalia populations in Switzerland were detected by flow cytometry (Meirmans et al, 1999; Calame and Felber, 2000). These and the present study suggest that tetraploids generally occur at low frequencies in mixed diploid-triploid Ruderalia populations.

\section{Breeding system of the cytotypes}

All diploid plants needed pollination for seed set and were thus sexual outcrossers. All triploid plants reproduced apomictically, except one, which produced some fertilized $2 n+n$ offspring. Richards (1970a) and Müller (1972) found few diploids in the offspring of triploids, indicating reductional egg cell formation. These triploids were considered to be facultative apomicts. The $\mathrm{G}_{1}$ of the triploids from our study population only produced triploid offspring after crosses with diploid pollen donors. There is no indication for triploid facultative apomicts in our samples.

The fact that all tetraploids carried more than two alleles per microsatellite locus rules out the possibility that they originated from somatic doubling of diploids (Ramsey and Schemske, 1998). All the nine tetraploids had unique multi-locus microsatellite genotypes, implicating that they were not clonal replicates, but must have had independent sexual origins.

The breeding system can provide information about the pathway of tetraploid formation. All the four adult tetraploids exhibited some elements of apomixis, viz. diplospory, parthenogenesis and autonomous endosperm development (Asker, 1980; Van Dijk et al, 2003), excluding the unlikely possibility that they arose by the fusion of two unreduced gametes produced by diploid sexuals (Ramsey and Schemske, 1998). 
The plant Tetra 5 possessed all elements of apomixis, but spontaneous seed set was lower than that of established triploid apomicts (0.95-0.99, unpublished results). Tetraploid offspring in $2 x-3 x$ crosses are formed by an unreduced $3 x$ pollen grain, inheriting the full apomictic genotype. Tas and van Dijk (1999) found that tetraploids in such crosses were full apomicts, although partly sterile.

Most of the offspring from Tetra 7 were apomictically produced, but low numbers of offspring were sexually produced. This tetraploid resembles the breeding behaviour of the so-called elegans aberrant described by Sørensen (1958). This disomic triploid $(2 n=23)$ produced besides apomictic offspring also low frequencies of reduced and fertilized offspring. Richards (1989) suggested that cytological instability could be due to high levels of transposon activity. Malecka (1973) and Van Baarlen (2001) reported occasional reductional female meiosis in triploid and tetraploid apomicts in the sections Palustria and Ruderalia. This can result in recombinational loss of elements of apomixis in individual florets.

The foreland tetraploid (Tetra F) produced a mixture of apomictic $(2 n+0)$ and sexual $(2 n+n)$ seeds. This lineage resembles the type $B$ triploid hybrids from $2 x-3 x$ crosses, which lack autonomous endosperm development, but do produce only unreduced egg cells that can develop parthenogenetically but sometimes become fertilized (Van Dijk et al, 2003).

The Tetra 1 lineage lacks parthenogenesis and produced offspring with increasing ploidy level upon fertilization. This phenomenon has been described by Stebbins (1950), who predicted that such cytotypes will 'polyploidize themselves out of existence' ( $p$ 389).

\section{Cytotype fitness}

Sexual diploids had a high seed set in the field. Apparently, sufficient insects and fertile pollen are available in this mixed population (cf. Sterk, 1987). In most diploid capitula, seed set is as high as in the triploids. However, in some individual capitula, the seed set was severely decreased, resulting in an overall lower viable seed set of the diploid sexuals than that of the triploid apomicts. Seed set in apomictic triploids was uniformly high, reflecting reproductive assurance.

Diploid sexuals produced more ovules per capitulum than triploid apomicts. A similar difference has been found by De Kovel (2001). The extra production of nonfertilized ovules could be regarded as a cost to sexual reproduction. On the other hand, in better years or circumstances, these ovules might become fertilized as well, increasing the fertility of diploid sexuals.

The tetraploids varied in fertility, because of the different modes of reproduction described above. The seed set of the apomictic tetraploid (Tetra 5) did not differ from the diploids. Nonetheless, Tetra 5 will produce less offspring because its germination rate was lower. Although two tetraploids (Tetra 1 and 7) produced more capitula than average, their number of offspring was not higher because the seed set per capitulum was very low. The average viable seed set of the tetraploids was much lower than of the diploids and triploids. In addition, the mortality of seedlings from tetraploids in the first weeks after germination was high (Verduijn, unpublished results). This suggests that tetraploid seedlings - at least from the investigated tetraploid mothers - will have a low survival chance in nature. Therefore, it is questionable whether the number of tetraploids in a mixed population can increase. This idea is consistent with the fact that all nine tetraploid plants were unique. Even of the full apomict Tetra 5, no clonal replicates were found.

\section{Pollen function}

Tetraploids are far better pollen donors than triploids. When used as pollen donors, tetraploids produce on average 28 times more triploid offspring on diploid sexual plants than do triploid fathers.

When triploids are used as pollen donors, low rates of tetraploid hybrids are formed, as well as probably some diploid hybrids. However, this latter class of hybrids cannot be distinguished from selfed diploid offspring in the present set-up. Both Morita et al (1990a) and Tas and Van Dijk (1999) found by using genetic markers that almost $90 \%$ of the offspring in $2 x-3 x$ crosses was due to selfing, caused by a breakdown of the SI system. Diploid offspring in $2 x-4 x$ crosses can only be due to selfing. Assuming also $90 \%$ selfing in our $2 x-3 x$ crosses, experimental $2 x-4 x$ crosses would produce a six times lower frequency of diploid offspring, suggesting that the pollen from tetraploids has a much reduced mentor pollen effect compared to pollen from triploids. The low hybrid production and the high selfing induction by triploid pollen donors are likely to be related to the high frequencies of aneuploid pollen grains produced by an irregular meiosis.

A reappraisal of the sexual-asexual cycle of Taraxacum Without interploidy gene flow, the cytotype frequencies depend entirely on their relative fitnesses. Assuming everything else being equal, reproductive assurance is expected to shift the balance towards the direction of the apomicts in years with poor pollination conditions. In years with good pollinator conditions, all sexual ovules may become fertilized and the balance may shift towards the sexuals. If, however, interploidy gene flow takes place, the cytotypes will influence each other's numbers more directly, because new apomictic clones will be formed by the sexuals. At the same time, the sexual gene pool will become enriched by genes from apomictic lineages.

The pathways of reproductive interaction and their quantitative relevance as measured in the present study are summarized in Figure 5. The production of diploid offspring by triploid facultative apomicts was not included, because we found no evidence for this in our study (we did detect one facultative apomictic tetraploid, but no facultative triploids in our samples). After fertilization by pollen from triploids and tetraploids, sexual diploids can produce diploid, triploid and tetraploid hybrid offspring as well as diploid selfed offspring owing to induced selfing. It should be noted, however, that although in experimental crosses the induction of selfing can be quite high marker studies indicate that induced selfing in the field is rare and restricted to places where outcross haploid 


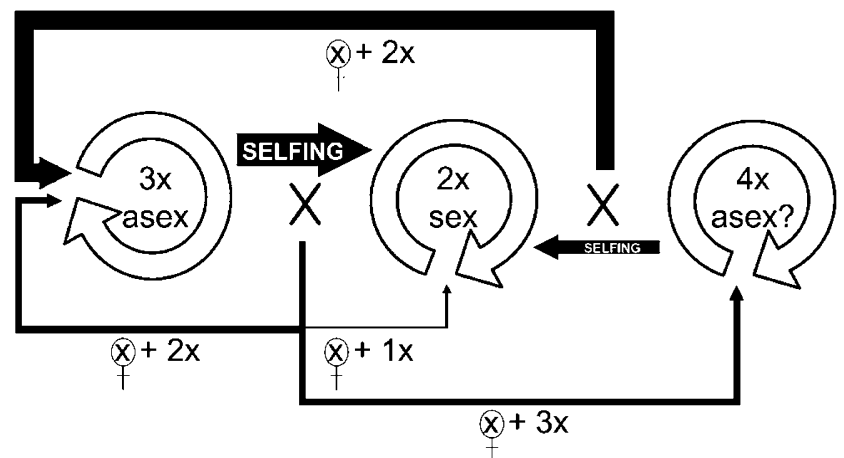

Figure 5 A schematic overview of the $2 x-3 x-4 x$ cycle of Taraxacum section Ruderalia. The thickness of the lines is indicative for the rate of formation of a certain cytotype after pollen flow in experimental crosses, as measured in this study.

pollen from other diploids is limited (Verduijn et al, in preparation).

The production of triploid and tetraploid hybrids on diploid sexual plants causes a decrease in the numbers of sexuals in each generation. This is the basic reason why hermaphroditic asexuals replace outcrossing sexuals rapidly in population genetic models (Charlesworth, 1980; Marshall and Brown, 1981; Joshi and Moody, 1998). However, our data show that the frequency of polyploid offspring on diploid sexuals is low, on average less than $2 \%$. This is probably because of the low frequencies of balanced $2 x$ and $3 x$ pollen produced by the triploids. The low pollen fertility of triploids will slow down the rate of replacement of sexuals considerably. Several papers have stressed the effect of pollen produced by apomictic triploids on diploid sexuals (Morita et al, 1990b; Mogie, 1992). In a theoretical study concerning the elimination of sexuals, Joshi and Moody (1998) assume that pollen produced by apomicts is fully fertile. Mogie (1992) considers that pollen from triploids had a strong impact on sexual diploids during the colonization after the ice age; triploids would have eliminated sexual diploids by hybridization. However, given the low pollen fertility of triploids, it is doubtful if hybridization could have such a strong impact on coexistence.

Hybridization between diploid sexuals and apomictic polyploid pollen donors is a source of new apomictic lineages. Although the loss of diploid seeds by hybridization is only a few per cent, still each year perhaps some 10000 new polyploid seeds could be formed in this Wageningen population via the $2 x-3 x-4 x$ pathway (assuming a population size of reproductive sexuals: 2500, two flower heads per plant, 100 seeds per flower head, $2 \%$ triploid or tetraploid offspring on sexual mothers). Some of these new polyploids will be full apomicts, but others may only possess one or two elements of apomixis, since apomixis is controlled by several unlinked loci (Van Dijk et al, 1999). Also, the degree of apomictic reproduction was found to vary strongly between newly formed apomicts (Tas and Van Dijk, 1999; De Kovel and De Jong, 2000). New apomictic clones with a low seed set will be selected against. In addition, new apomicts have to compete with sexuals and the already established apomicts. Only the new clones that are competitively superior or find a new unoccupied niche will be able to establish and proliferate.
This leaves the question, which is the most important pathway of new clone formation. Although the chance of a $2 x-4 x$ cross in the field to occur is low because of low tetraploid frequency, in such a cross 28 times more triploid offspring will be produced. Tetraploids thus form a bridge in the production of triploids. So far, this role of tetraploids has been neglected in the Taraxacum sexual-asexual cycle (eg Nakayama et al, 2002). Modelling the dynamics of sexual-asexual cycles suggests that tetraploids can play a significant role in the dynamics of the sexual-asexual cycle even when the segregation of apomixis is taken into account (Van Dijk and Verduijn, in preparation).

\section{Acknowledgements}

This paper is publication 3312, NIOO-KNAW, Netherlands Institute of Ecology. We would like to thank Geja Gortzak for practical assistance and Eric Bleeker for electronic artwork and comments on the manuscript.

\section{References}

Asker S (1980). Gametophytic apomixis: elements and genetic regulation. Hereditas 93: 277-293.

Berthaud J (2001). Apomixis and the management of genetic diversity. In: Savidan Y, Carman JG, Dresselhaus T (eds) The Flowering of Apomixis: From Mechanism to Genetic Engineering, CIMMYT, IRD, EC: Mexico, DF. pp 243.

Calame FG, Felber F (2000). Distribution of diploid sexual and triploid apomictic dandelions (Taraxacum sect Ruderalia) along two altitudinal gradients in Switzerland. Bot Helv 110: $109-114$.

Carman JG (1998). Asynchronous expression of duplicate genes in angiosperms may cause apomixis, bispory, tetraspory, and polyembryony. Biol J Linn Soc 61: 51-94.

Charlesworth B (1980). The cost of sex in relation to mating system. J Theor Biol 84: 655-671.

De Kovel CGF (2001). The significance of sexual reproduction for local adaptation in Taraxacum. PhD Thesis, University of Utrecht: Utrecht.

De Kovel CGF, De Jong G (2000). Selection on apomictic lineages of Taraxacum at establishment in a mixed sexualapomictic population. J Evol Biol 13: 561-568.

De Wet JMJ (1968). Diploid-tetraploid-haploid cycles and the origin of variability in Dichantium agamospecies. Evolution 22: 394-397.

De Wet JMJ, Harlan JR (1970). Apomixis, polyploidy and speciation in Dichantium. Evolution 24: 270-277.

Den Nijs JCM, Sterk AA (1980). Cytogeographical studies of Taraxacum sect. Taraxacum (= sect. Vulgaria) in Central Europe. Bot Jahrb Syst 101: 527-554.

Den Nijs JCM, Sterk AA (1984a). Cytogeography and cytotaxonomy of some Taraxacum sections in Belgium and Northern France. Acta Bot Neerl 33: 431-455.

Den Nijs JCM, Sterk AA (1984b). Cytogeography of Taraxacum sectio Taraxacum and sectio Alpestria in France and adjacent parts of Italy and Switzerland, including some taxonomic remarks. Acta Bot Neerl 33: 1-24.

Elzinga D, Van der Kamp J, Den Nijs JCM, Sterk AA (1987). Cytogeography and ecology of diploids and triploids of Taraxacum section Taraxacum in South Limburg, Netherlands. Proc Kon Ned Acad Wetensch 90: 431-442.

Falque M, Keurentjes J, Bakx-Schotman JMT, Van Dijk P (1998). Development and characterization of microsatellite markers in the sexual-apomictic complex Taraxacum officinale (dandelion). Theor Appl Genet 97: 283-292.

Fürnkranz D (1960). Cytogenetische Untersuchungen an Taraxacum im Raume von Wien. Österr Bot Z 107: 310-350. 
Fürnkranz D (1961). Cytogenetische Untersuchungen an Taraxacum im Raume von Wien. II Hybriden zwischen T. officinale und T. palustre. Österr Bot Z 108: 408-415.

Harlan JR, De Wet JMJ (1975). On Ö. Winge and a prayer: the origins of polyploidy. Bot Rev 41: 361-390.

Hughes J, Richards AJ (1988). The genetic structure of populations of sexual and asexual Taraxacum (dandelions). Heredity 60: 161-171.

Jenniskens M-JPJ, Wetzels PCJ, Sterk AA (1984). Aspects of the flowering ecology of taxa of Taraxacum sect Taraxacum. Bot Jahrb Syst Planzengesch Planzengeogr 104: 369-400.

Joshi A, Moody ME (1998). The cost of sex revisited: effects of male gamete output of hermaphrodites that are asexual in their female capacity. J Theor Biol 195: 533-542.

Malecka J (1973). Problems of the mode of reproduction in microspecies of Taraxacum section Palustria Dahlstedt. Acta Biol Cracov Ser Bot 16: 37-87.

Marshall DR, Brown AHD (1981). The evolution of apomixis Heredity 47: 1-15.

Meirmans PG, Calame FG, Bretagnolle F, Felber F, Den Nijs JCM (1999). Anthropogenic disturbance and habitat differentiation between sexual diploid and apomictic triploid Taraxacum sect. Ruderalia Folia Geobot 34: 451-469.

Menken SBJ, Smit E, Den Nijs JCM (1995). Genetical population structure in plants: gene flow between diploid sexual and triploid asexual dandelions (Taraxacum section Ruderalia) Evolution 49: 1108-1118.

Mogie M (1992). The Evolution of Asexual Reproduction in Plants, Chapman \& Hall: London.

Morita T, Menken SBJ, Sterk AA (1990a). Hybridization between European and Asian dandelions (Taraxacum section Ruderalia and section Mongolica). 1. Crossability and breakdown of self-incompatibility. New Phytol 114: 519-529.

Morita T, Sterk AA, Den Nijs JCM (1990b). The significance of agamospermous triploid pollen donors in the sexual relationships between diploids and triploids in Taraxacum (Compositae). Plant Spec Biol 5: 167-176.

Müller U (1972). Zytologisch-embryologische Beobachtungen an Taraxacum-Arten aus der Sektion Vulgaria Dahlst. in der Schweiz. Berichte Geobotanisches Institut ETH, Stiftung Rübel 41: $48-55$.

Nakayama Y, Seno H, Matsuda H (2002). A population dynamic model for facultative agamosperms. J Theor Biol 215: 253-262.

Nogler GA (1984). Gametophytic apomixis. In: Johri BM (ed) Embryology of Angiosperms, Springer Verlag: Berlin. pp 475-518.

Okabe S (1956). On the nature of incompatibility alleles in Taraxacum elatum $x$ T. longeappendiculatum (Self-incompatibility studies in Taraxacum 1). Bot Mag Tokyo 69: 592-597 (in Japanese with English summary).

Ramsey J, Schemske DW (1998). Pathways, mechanisms and rates of polyploid formation in flowering plants. Annu Rev Ecol Syst 29: 467-501.

Richards AJ (1970a). Eutriploid facultative agamospermy in Taraxacum. New Phytol 69: 761-774.

Richards AJ (1970b). Hybridisation in Taraxacum. New Phytol 69: 1103-1120.
Richards AJ (1989). A comparison of within-plant karyological heterogeneity between agamospermous and sexual Taraxacum, as assesed by the nucleolar organizer chromosome. Plant Syst Evol 163: 177-185.

Richards AJ (1997). Plant Breeding Systems, 2nd edn. Chapman \& Hall: London.

Roetman E, Den Nijs JCM, Sterk AA (1988). Distribution and habitat range of diploid, sexual dandelions (Taraxacum section Vulgaria), a Central European flora element in the Netherlands. Acta Bot Neerl 37: 81-94.

Rogstad SH (1992). Saturated NaCl-CTAB solution as a means of field preservation of leaves for DNA analyses. Taxon 41: 701-708.

Savidan Y, Pernes J (1982). Diploid-tetraploid-dihaploid cycles and the evolution of Panicum maximum Jacq. Evolution 36: 596-600.

Stebbins GL (1950). Variation and Evolution in Plants, Colombia University Press: New York.

Sørensen T (1958). Sexual chromosome-aberrants in triploid apomictic Taraxaca. Bot Tidsskr 54: 1-22.

Sterk AA (1987). Aspects of the population biology of sexual dandelions in the Netherlands. In: Huiskes AHL, Blom CWPM, Rozema J (eds) Vegetation Between Land and Sea, Junk: Dordrecht. pp 284-290.

Sterk AA, Den Nijs JCM, Kreune W (1982). Sexual and agamospermous Taraxacum species in the Netherlands. Acta Bot Neerl 31: 227-237.

Tas ICQ, Van Dijk PJ (1999). Crosses between sexual and apomictic dandelions (Taraxacum). I. The inheritance of apomixis. Heredity 83: 707-714.

Tschermak-Woess E (1949). Diploides Taraxacum vulgare in Wien und Niederöstereich. Österr Bot Z 96: 56-63.

Van Baarlen P (2001). Apomixis in Taraxacum: an embryological and genetic study. PhD Thesis, Wageningen University: Wageningen.

Van Baarlen P, Van Dijk P, Hoekstra RF, De Jong JH (2000). Meiotic recombination in sexual diploid and apomictic triploid dandelions (Taraxacum officinale L.). Genome 43: 827-835.

Van Dijk PJ, Tas ICQ, Falque M, Bakx-Schotman T (1999). Crosses between sexual and apomictic dandelions (Taraxacum). II. The breakdown of apomixis. Heredity 83: 715-721.

Van Dijk PJ, Van Baarlen P, De Jong JH (2003). The occurrence of phenotypically complementary apomixis-recombinants in crosses between sexual and apomictic dandelions (Taraxacum officinale). Sex Plant Repr 16: 71-76.

Van Dijk PJ, Verduijn MH. Modeling coexistence of sexual and apomitic dandelions. In preparation.

Verduijn MH, Van Dijk PJ, Van Damme JMM (2004). Distribution, phenology and demography of sympatric sexual and asexual dandelions (Taraxacum): geographic parthenogenesis on a small scale. Biol J Linn Soc (in press).

Verduijn MH, Van Dijk PJ, Van Damme JMM. Hybridisation and the induction of selfing in a mixed sexual - asexual dandelion population. In preparation.

Wang H, Qi M, Cutler AJ (1993). A simple method of preparing plant samples for PCR. Nucleic Acids Res 21: 4153-4154. 